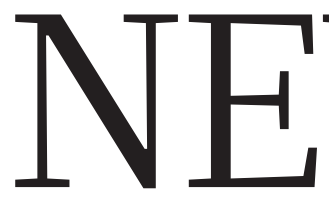

ENVIRONMENT Shale-oil

boom carries extra

carbon cost $\mathbf{p . 2 9 0}$
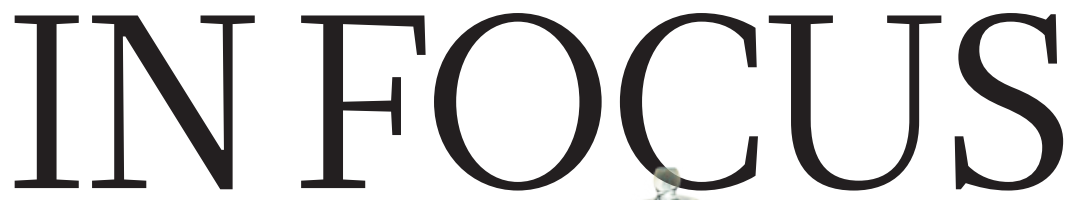

$x-$

SPACE Mars-rover team feels pressure to pick up the pace $\mathbf{p . 2 9 2}$
RESOURCES Will deep-sea mining finally take the plunge? p.294
RESEARCH Marathon

experiments, and their lasting rewards $\mathbf{p . 3 0 0}$

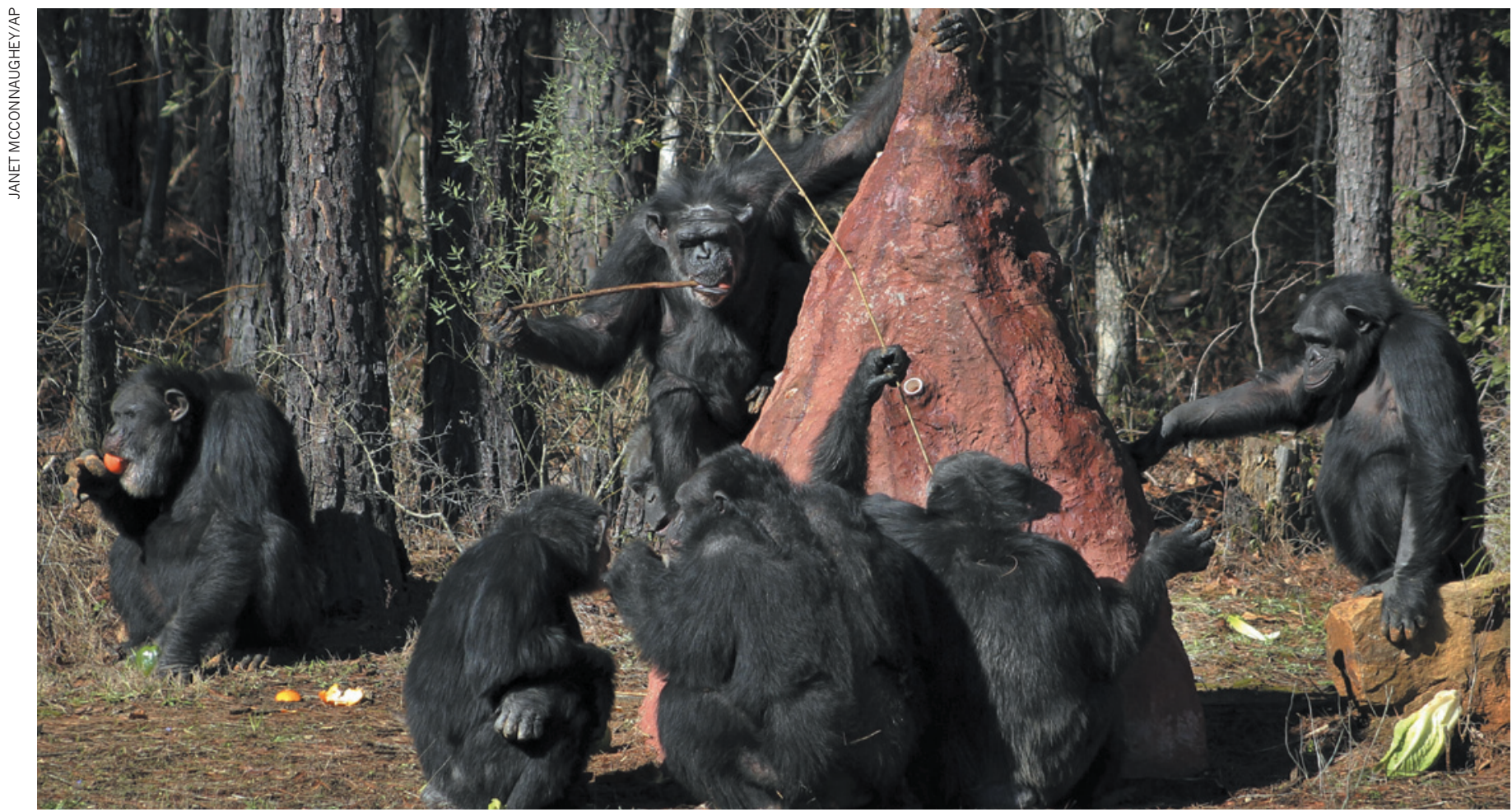

Chimp Haven in Louisiana is the final destination for retired NIH research animals.

\title{
ETHICS
}

\section{Time called on chimp work}

\section{NIH likely to retire hundreds of government-owned chimpanzees.}

\section{BY MEREDITH WADMAN}

$\mathrm{G}$ overnment-funded chimpanzee research in the United States has been on notice for more than a year. This month, its time is probably up.

First came a report from the Institute of Medicine (IOM) in December 2011, which found that most chimp research is unnecessary, given that almost all questions can be explored in other animal models or in vitro.

Now Francis Collins, director of the National Institutes of Health (NIH), is expected to accept the bulk of the recommendations from an NIH working group that would retire several hundred agency-owned chimpanzees, leaving a core of just 50 animals available for
NIH research. The working group, which on 22 January released proposals for how the $\mathrm{NIH}$ should implement the IOM report, also said that the agency should end six of the nine invasive studies that it funds. And the other three would be allowed to continue only if the animals' environments are substantially improved, probably at great expense.

Should Collins accept the recommendations, it would be "a milestone in animal-research practice and policy, and an endorsement of the conclusion that there is a rapidly decreasing need for the use of chimpanzees in research", says Jeffrey Kahn, a bioethicist at Johns Hopkins $\rightarrow$ NATURE.COM

For more on the controversy over chimp research: go.nature.com/ugfawq
University in Baltimore, Maryland, who led the 2011 IOM committee.

The working group did not identify which experiments it thought should end, so NIH researchers will learn the fate of their studies only after Collins's decision. Several chimpanzee researchers contacted by Nature declined to speak on the record about their work, but some lamented that unique science would disappear.

The nine invasive biomedical experiments include one that is searching for an infectious trigger for primary biliary cirrhosis, a disease that slowly destroys the liver and is fatal without a transplant. Another, conducted by a biotechnology company, tests an agent that binds to molecular targets on immune cells and is intended to shut down the immune 
- response that causes diseases such as rheumatoid arthritis and lupus. The candidate drug's targets occur in only two species: humans - in whom safety tests of the compound would be ethically impermissible - and chimpanzees. If the study is killed, "this line of investigation will probably have to stop", says one observer with knowledge of the study.

Although the IOM committee was unanimous in declaring chimpanzees unnecessary for almost all invasive research, it was split on whether the animal is essential for developing a vaccine against hepatitis $C$, which kills some 350,000 people globally each year. The chimpanzee is the only animal model that can test whether an immune response to a candidate vaccine would protect against hepatitis $\mathrm{C}$ infection. One of the nine studies now in jeopardy explores why the immune response in chimpanzees often cannot clear hepatitis $\mathrm{C}$ infections.

"Everybody working with chimpanzees in the hepatitis $C$ field realizes that they are really unique animals," says Stanley Lemon, who studies hepatitis $\mathrm{C}$ at the University of North Carolina, Chapel Hill, and who resigned from the NIH working group last year. "But you have to balance that against the weight of human morbidity and mortality."

The working group also recommended that five of 13 behavioural and comparative-genomics studies should end. The Yerkes National Primate Research Center in Atlanta, Georgia, hosts some of these studies, which include an assessment of the roles of the hormones vasopressin and oxytocin in social cognition, and a look at how genes and early social experiences affect brain development and behaviour.

Even if Collins allows the Yerkes studies to continue, the recommendation for new housing requirements could doom the projects. The working group proposed the provision of 6.1 vertical metres of climbing structure and 93 square metres of space for each animal; fresh materials for daily construction of nests; foraging opportunities; and housing in social groups of at least seven. "We estimate it could cost tens of millions of dollars for our centre alone to renovate space that will have limited use given our ageing colony," says Yerkes spokeswoman Lisa Newbern.

Some ethicists say that if Collins embraces the recommendations, his decision will not only mark the end of most government-supported chimpanzee research, but also raise questions about work on other non-human primates. The NIH supports a network of primate research centres that houses some 27,000 non-human primates of 20 species. "We're not going to suddenly decide that all primates have got to be retired," says Gregory Kaebnick, a research scholar at the Hastings Center in Garrison, New York, who last month led a study on changing ethical views on animal research. "But we might find ourselves trying to reassess the way we've been using them." -

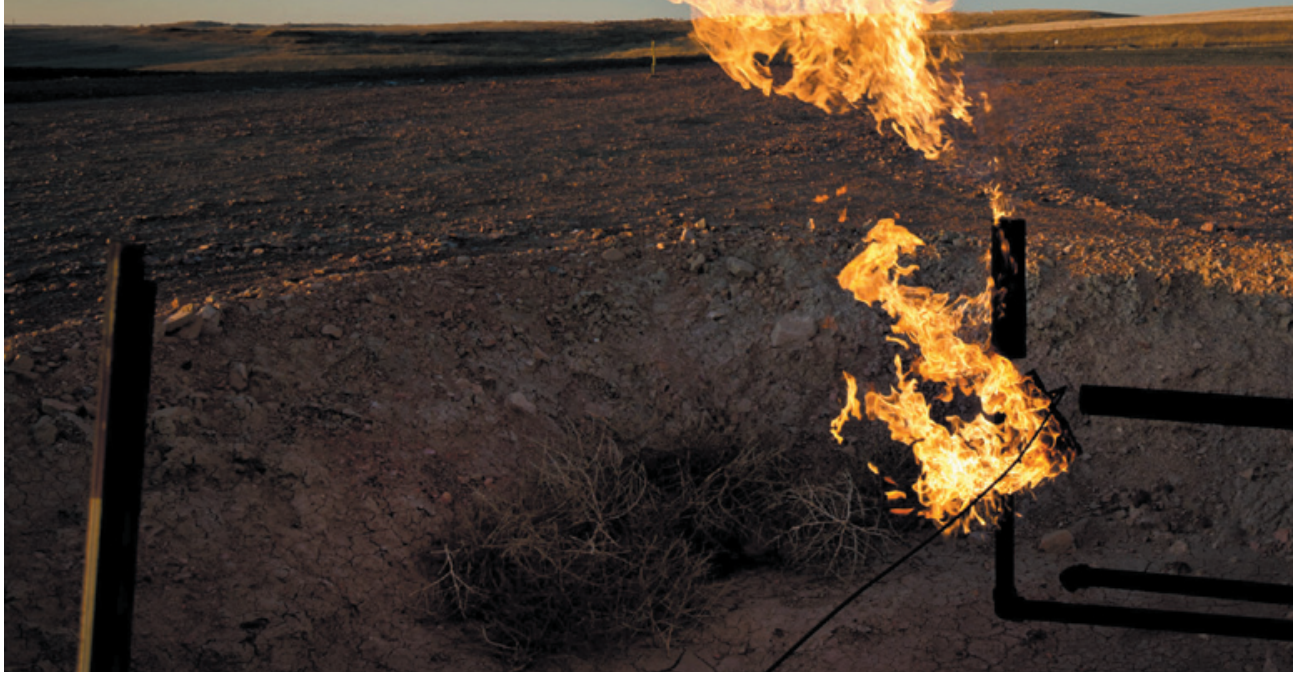

Natural gas from oil wells in North Dakota is often burned rather than captured and sold.

ENERGY

\section{Oil boom raises burning issues}

\section{Unburned methane could be adding to the environmental impact of gas flares in North Dakota.}

\section{BY JEFF TOLLEFSON}

W hen Paul Shepson flew his twinpropeller Beech aircraft over the Williston Basin in North Dakota last June, the perverse economics of a modern-day energy bonanza were on vivid display. Shepson, an atmospheric chemist at Purdue University in West Lafayette, Indiana, saw 10-metre-high flames writhing in the wind as shale-oil producers burned off the natural gas that was coming up along with the oil - a valuable resource that here, far from gas pipelines, is just a nuisance.

In 2011, North Dakota's oil producers flared around 1.4 billion cubic metres of natural gas, according to the Energy Information Administration (EIA) in Washington DC. That was nearly $32 \%$ of the total amount of gas produced by the state, and enough to heat around 700,000 houses. And the flaring increased in 2012. Scientists are just beginning to assess how the carbon dioxide from the flames adds to the climate footprint of the oil, and how black carbon and other pollutants affect local air quality.
But Shepson has also begun to detect evidence of a hidden threat: plumes of pure methane - a much more potent greenhouse gas than $\mathrm{CO}_{2}-$ that is either leaking from the oil and gas infrastructure or being vented by extractors who are not flaring. Although he has yet to quantify the methane emissions, Shepson says that the energy coming out of the basin could have a steeper environmental price than many realize.

Over the past several years, companies have been using the same hydrofracturing technologies that have spurred a broader US gas rush to drill thousands of oil wells into the Bakken shale formation, which stretches across North Dakota, Montana and the Canadian province of Saskatchewan. High oil prices are driving the boom, which some predict could help to make the United States the world's largest oil producer by 2020. Companies that build pipelines and gas-processing plants simply cannot keep up.

Some $65 \%$ of the oil from the Bakken shale is now being shipped out by rail. But the raw natural gas that bubbles up along with it - a mixture of lighter liquid hydrocarbons and 